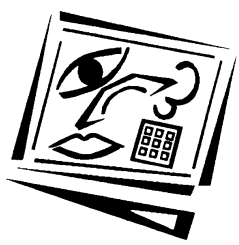

\title{
The digital video database: A virtual learning community for teacher education
}

\author{
Winnie Wing-mui So, Vincent Hing-keung Hung and Walker Yee-wing Yip \\ The Hong Kong Institute of Education
}

\begin{abstract}
This research started with the design and implementation of an online digital video database, followed by a study of how three student teachers used it in building a virtual learning community that enabled the sharing of teaching practices during their first teaching practicum in the teacher education program. The student teachers made use of teaching practice videos that were edited into 'learning objects' ready for peer evaluation. The peer evaluation was conducted by an online discussion forum among community members, which provided the data for analysis. The findings give insight into how comments and feedback flowed within the learning community, and how the videos in the form of learning objects helped to generate various categories of teaching practices. Finally, a follow up focus group discussion provided useful data regarding the possibilities and limitations of creating a learning community centred on sharing constructed learning objects in an online digital video database.
\end{abstract}

\section{Introduction}

In recent years, educators have sought to integrate computer and telecommunications technologies into the classroom, to improve the quality of both learning and teaching experiences. In teacher education, one approach is to focus on facilitating social interaction via an online sharing platform, so that students can learn from sharing and interaction (Steketee, 2006). In today's digital world, the construction of a database for sharing and interaction need not be a difficult technical challenge. Instead, the major challenges are likely to be in editing and shaping resources - especially videos - into meaningful learning objects for uploading to a database for sharing and searching. A database may help to create a learning community in which users communicate, share video resources, discuss applications, and learn from one another. The present study aims to investigate two aspects of the development of a digital video database. Firstly, we explored the technical aspects of uploading videos for sharing of teaching practices. Secondly, we examined the application of this technological development to teacher education.

\section{Technological development of the video database}

\section{Learning objects in the video database}

Recently, videos have become increasingly popular resources in higher education, especially in teacher education, in large part because they can be used to demonstrate good practices and for performance analysis in authentic situations (Ching, 2006). However, production of video with high quality often requires a lot of time, costly equipment and labour, making it questionable whether it is worthwhile to produce a 
video recording to be used only by a specific teacher in a specific class. Another problem is about cross-platform compatibility - video formats have evolved rapidly over the past ten years, from analogue VHS to digital media, and there are still many barriers to sharing videos on a common platform. In other words, technical advances and the emergence of digital video do not necessarily facilitate practical management, classification, retrieval and reuse of video resources.

One possible solution to these limitations is the use of text based retrieval techniques in which video content and context are annotated by free text, making them searchable by keyword (Marques \& Furht, 2002). Once integrated into a searchable database, videos become learning objects that can be shared and reused. To maximise their effectiveness as learning objects, videos should be small and unified in format so that they can be shared across different digital platforms. For example, streaming and downloadable video in Windows Media Video (WMV) format and MPEG format are two basic unified digital video formats that can be shared by users with Internet access. Both formats can be viewed in Windows Media Player, which is bundled with every Windows XP and the new Vista operating system. For the reuse of video aiming at a specific teaching purpose, MPEG video allow users to download and save video files for further editing and reuse.

From the perspective of a learning object economy, resources are often conceptualised as blocks of content that interlink to produce a course. Analogous to Lego bricks, these blocks can be recombined with other blocks and reused in a different course (Littlejohn, 2003). Wiley (2000) defined learning objects as any digital resources that can be reused to support learning. Learning objects produced by publishers, teachers, support staff and even students, are stored in digital databases, where they can be easily accessed, recombined and reused within online courses (Duncan \& Ekmekcioglu, 2003). More recently, Haughey and Muirhead (2005) conceived of learning objects as an effective and efficient means for providing virtual content that could be shared with others.

To maximise widespread utilisation, standardisation of learning objects is an essential prior condition (Littlejohn, 2003). The digital video database should have the potential to store various video formats including AVI, MPEG, MOV and streaming WMV. This ensures interoperability of resources between different electronic environments and platforms such as Windows and Macintosh. With an effective classification system, it is easier for users to find what they are looking for in a database (Littlejohn, 2003).

\section{Major components in the digital video database}

The access to the video database is password controlled and public access is not permitted. The major features of the digital video database include the Video Vault, Transaction Bin and Video Analysis (Figure 1). The Video Vault allows the uploading of video clips in MPEG, ASX, WMV or MOV format by individual users. The videos can then be shared for viewing and/ or downloading under the Transaction Bin (Figure 2). The streaming rate of WMV video is set in between $300 \mathrm{~kb} / \mathrm{s}$ to $700 \mathrm{~kb} / \mathrm{s}$, fulfilling both Internet and intranet user needs (Figure 3). The Video Communication Panel under the Transaction Bin is for the annotation of video clips. Users can create video bookmarks in videos by noting typical attributes, such as segment titles and short content descriptions, for easy classification. Together, the Annotation, Video Bookmark and Classification functions can improve the efficiency of Video Analysis, making it 
easy to locate clips for analysis and research by keyword searches of titles and content descriptions (Figure 4).

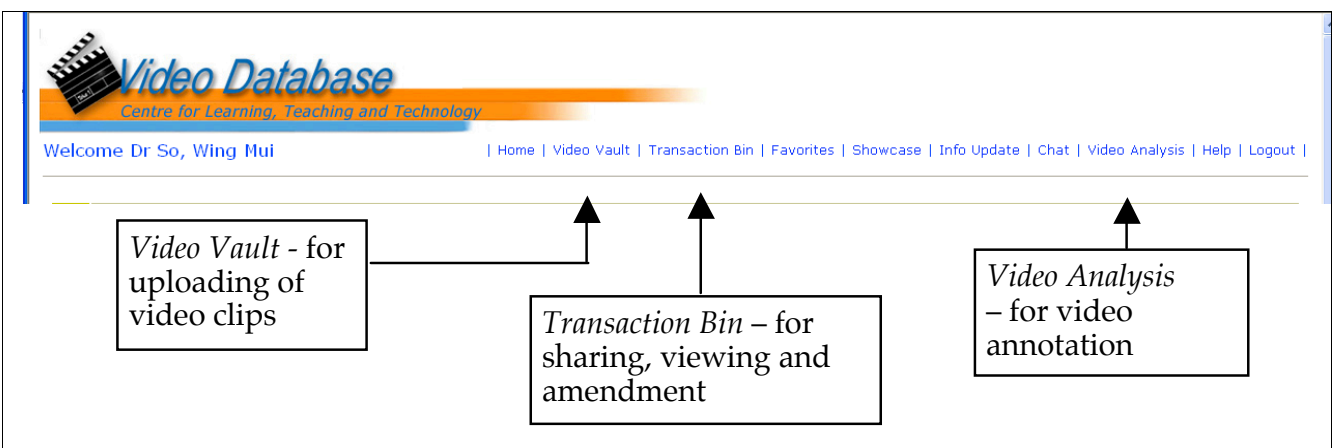

Figure 1: The major features of the video database

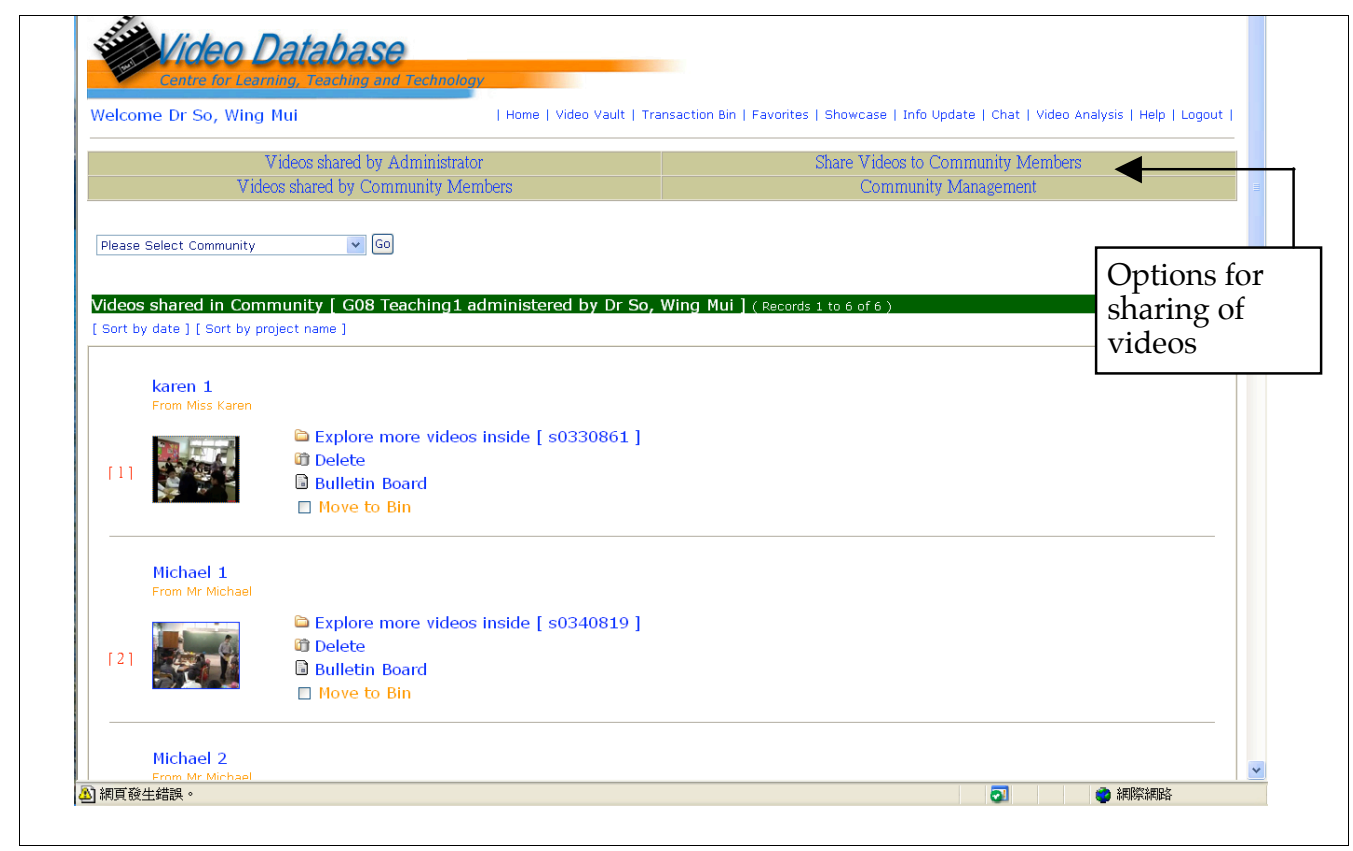

Figure 2: The Transaction Bin for sharing of videos

\begin{tabular}{|c|c|}
\hline Video Format (Right click to download) -----> No of download: 250 & Video Viewing -----> \\
\hline Mpeg-1 (320×288) & Instant Play \\
\hline Mpeg-1 (720x576) & Instant Play \\
\hline Streaming WMV (300K Standard) & Instant Play \\
\hline Streaming WMV (700K Standard) & Instant Play \\
\hline Streaming WMV (700K Full Screen) & Instant Play \\
\hline Quick-Time 320 × 240 256Kbps (15fps) & Instant Play \\
\hline
\end{tabular}

Figure 3: The various streaming rate of videos 


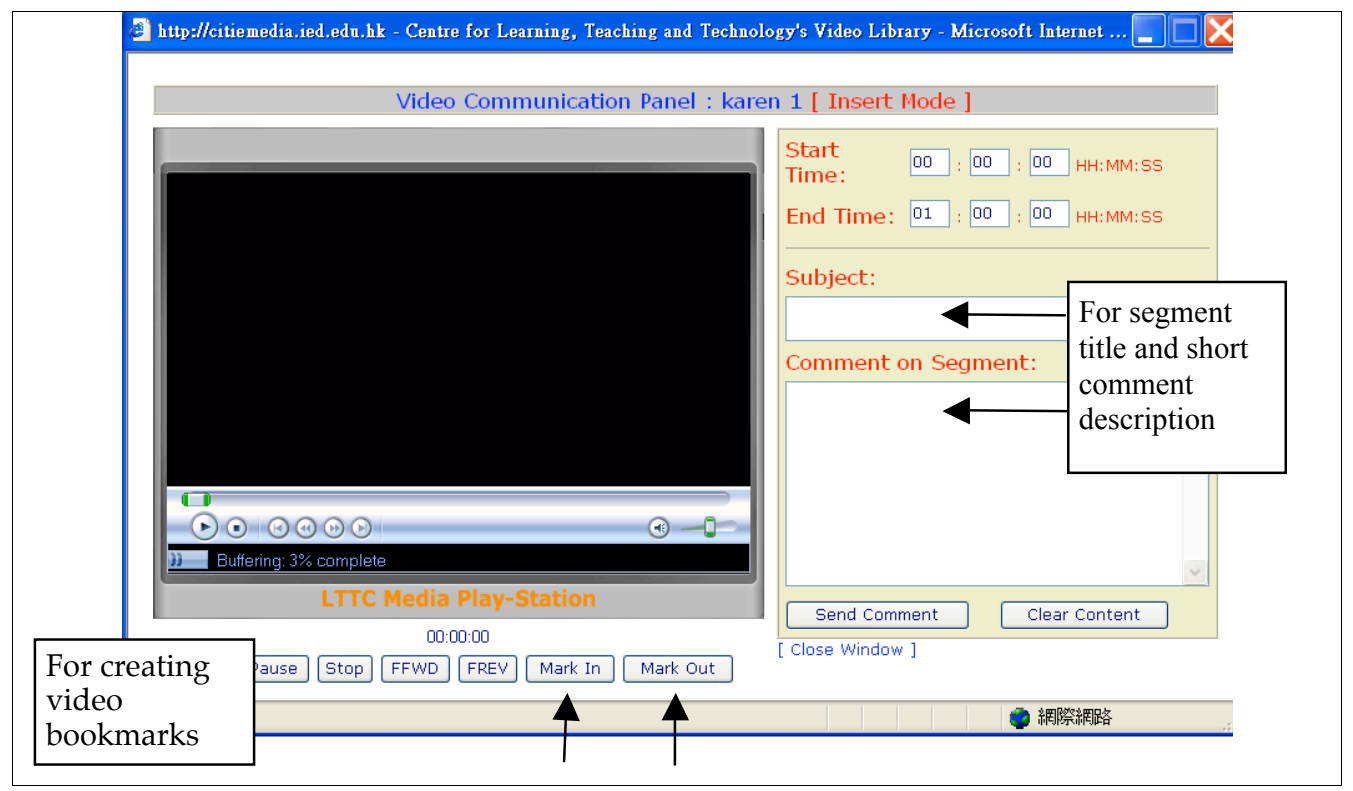

Figure 4: Interface of the Video Communication Panel

The Transaction Bin was initially designed to assist in the post-production of video teaching resources. Rough cut or finalised post-production video clips can be dropped into the Transaction Bin of an individual user for viewing and further amendment (Figure 5). All videos in transaction can be accessed from specific hyperlinks. With this function, videos can be distributed to a large number of users at any time without any further videotape duplication. With the additional implementation of a built in Video Communication Panel, users can post comments related to any video segment, informing the system administrator to follow up or update. The main design principle of the Transaction Bin is to improve the transaction rate, save time and reduce the use of storage devices and consumable materials (e.g. disk space, CDs, etc).

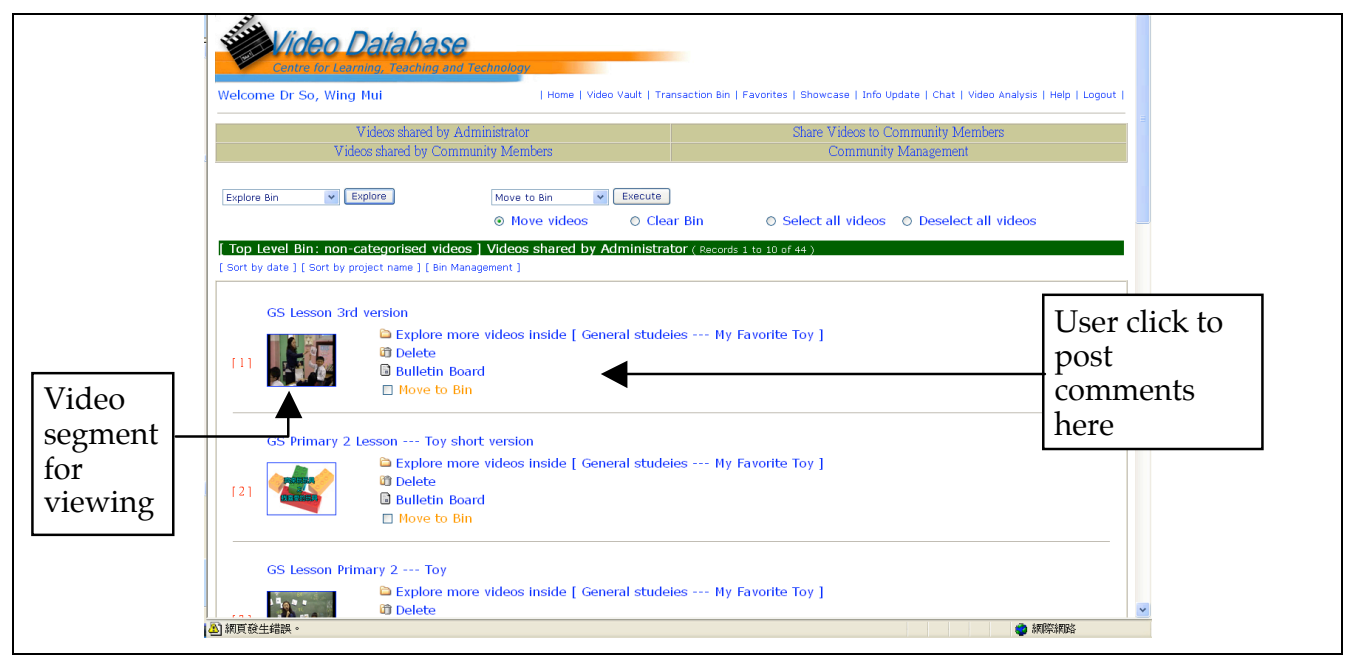

Figure 5: Interface of the Transaction Bin 


\section{Application of video database in teacher education}

\section{The learning community for knowledge building}

Under rapid technological changes in society, education faces great challenge to keep up with changes and to adapt them to classroom teaching. Bereiter (2003) argued that the challenge is not only to keep up with the change but to produce knowledge. Scardamalia \& Bereiter (2002) defined knowledge building as the production and continual improvement of ideas of value to a community. Knowledge building involves access to current knowledge by cultural transmission, new knowledge absorption, and then knowledge building (Bereiter, 2003). Citing the research examples from knowledge based businesses, Bereiter (2003) lists three areas of concern regarding knowledge building:

\section{Community knowledge}

The shared knowledge must be assessable, practical and of epistemic value.

Assessable and practical might refer to workable designs and plans. Epistemic value might refer to theories, interpretations or criticisms that could enable advancement of knowledge.

\section{Epistemic agency}

All community members should have shared objectives, workable plans, and accept collective responsibility for achieving the objective.

\section{Idea improvement}

Knowledge building is not an isolated idea for specific activity. The success of knowledge building requires sustained idea improvement integrating any big or small details contributed by members.

Educational reforms and technological advancement have played significant roles in the promotion of online knowledge sharing, e-learning systems, and the formation of virtual learning communities (Kurubacak, 2005; Marchionini \& Geisler, 2002). Such communities are vital because effective learning occurs where active social communication and interaction are triggered. An e-learning community is not only a place where individuals learn from other individuals but also where the community itself learns as a group (Tu \& Corry, 2002). Research has shown that online discussion helps students understand course objectives, provides 'authentic' applications and promotes interaction and critical thinking (Wickersham \& Dooley, 2006). The major challenge, then, is to develop the best environment for learning based on computer orientated communication (Luppicini, 2003).

Khine and Lourdusamy (2003) had once successfully implemented collaborative learning into teacher education under the Conversant Media platform with video annotation. Twenty-five student teachers were invited to participate in a pilot project to reflect on instructional issues in authentic teaching through online discussion in a computer laboratory. Three video clips about authentic classroom teaching were shown to the student teachers. They then gave feedback concerning the clips by video annotation through the Conversant Media platform in the computer laboratory. Though the pilot study demonstrated a breakthrough in using video annotation to enhance students' reflection on instructional issues, further technological breakthrough is expected on longer periods of video produced in streaming formats for web based annotation and discussion out of the laboratory. 


\section{Evolving into a learning community with the video database}

The video database is an online discussion platform that can cater for the sharing and annotation of teaching practice videos up to 35 minutes. An important milestone for the video database is the development of Video Communication Panel and Bulletin Board for community interaction. 'Mark-In', 'Mark-Out' and 'Comment on Segment' are essential features of the panel. With the purpose of highlighting noteworthy video segments for discussion, new and shorter video segments can be re-produced by using 'Mark-in' and 'Mark-out' editing buttons. Corresponding comments or suggestions can then be posted along with the marked and excerpted segments. To achieve knowledge building, other community members can also view and reply to comments or suggestions using the Video Bookmark (Haga, 2004). The playback of the video is controlled by using the basic play, pause, stop, rewind and fast forward buttons. In addition, time code of the video, theme of teaching objectives and comments are all displayed in the Video Communication Panel. Figure 6 shows an interface of Video Bookmark with two areas: 'Mark-In' and 'Mark-Out', and 'Comment on Segment'. Though English is the language of instruction at the video database, users can make comments in either English or Chinese (which is their mother tongue).

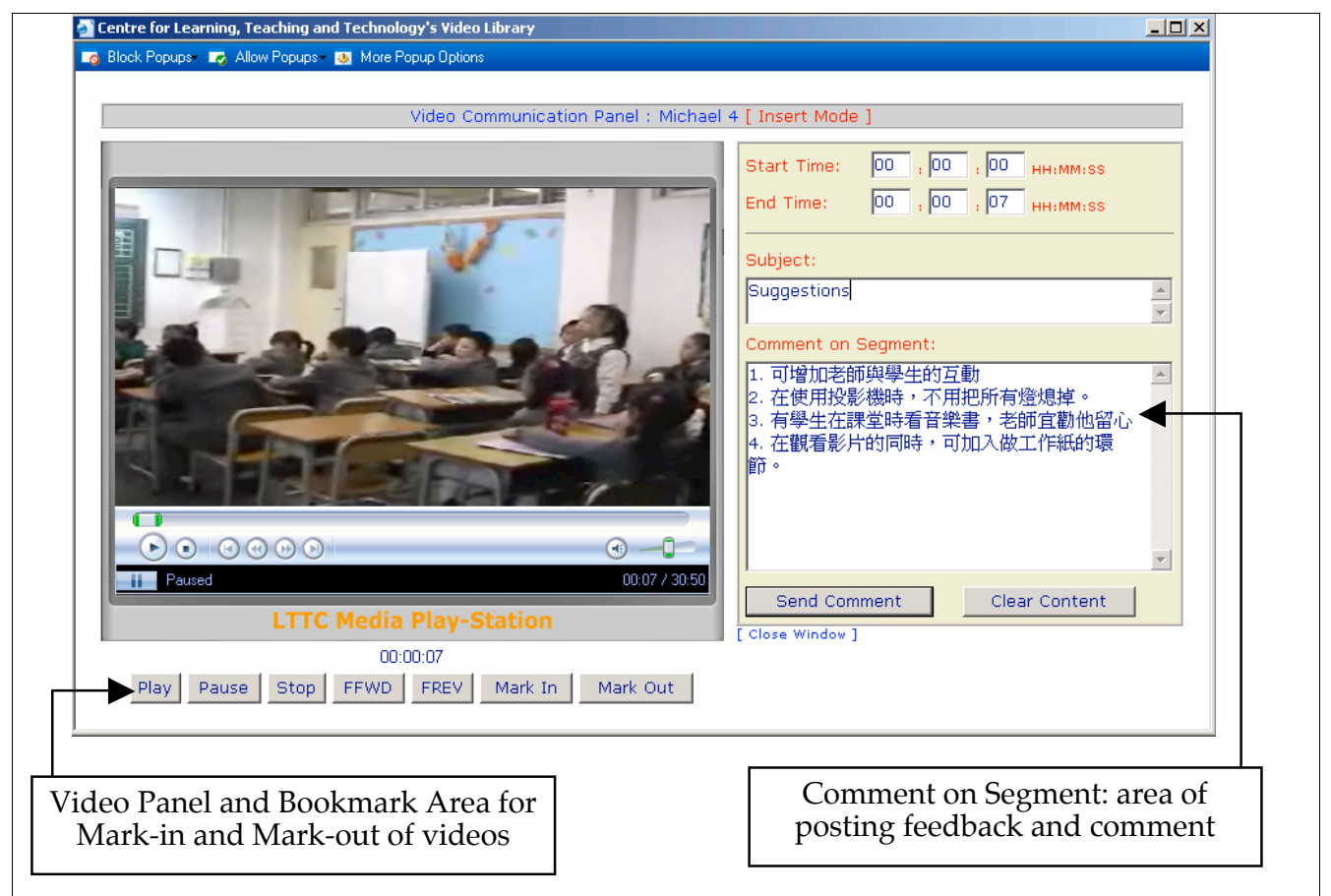

Figure 6: Comments on the Video Communication Panel

The Bulletin Board interface illustrates a new technique on how users can manage a digital video database by using text based retrieval technique. Figure 7 shows the Bulletin Board interface with three components. The Bulletin Board header displays the video title, video provider, a button for further comment and a button for the conversion of feedback and comments into PDF file format (Figure 8). This enhances portability, compatibility and sharing, as PDF files can be saved or emailed, passing on discussion threads along with the created video segment. The Theme Area is for the 
display of the title, reply button and a hyperlink to the segment created by the users and community members. Through the hyperlink, the segment can be viewed for further comment and feedback. The Discussion Forum displays responses to the segment marked by members while watching the videos at the Video Communication Panel.

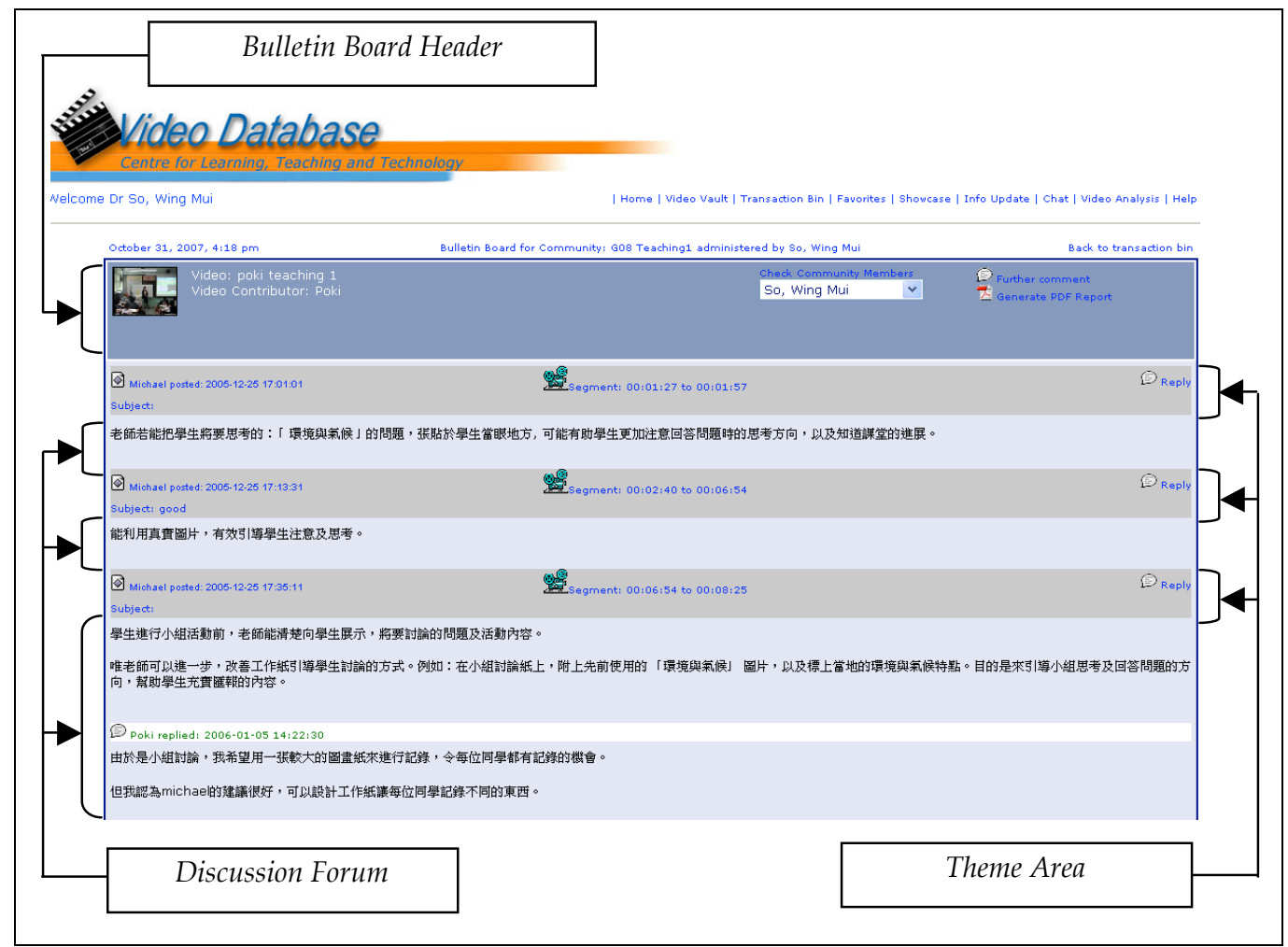

Figure 7: Interface of the Bulletin Board

\section{The design of the study}

\section{Objectives of the study}

The initial design and development of the online digital video database was to store self produced videos, and it gradually evolved into an interactive resource database for supporting teacher education. The application of the online video database was first introduced to three student teachers to build a small learning community for sharing of their teaching practices during their practicum period. Though the number of participants was small, it was manageable in the initial use of the new technology for the collection of meaningful data. Besides, a small number of participants allowed in depth analysis which is helpful for better understanding the pattern of sharing and communication. The aim of this study was to investigate how this interactive resource database supported student teachers in constructing knowledge concerning good practices of teaching during their first teaching practicum. The questions that guided the research process are as follows. 
- What is the flow of comments within the learning community?

- What are the nature and categories of responses posted by the community members?

- How do student teachers learn about teaching through the learning community and video database?

- What are the difficulties in creating a learning community with a video database?

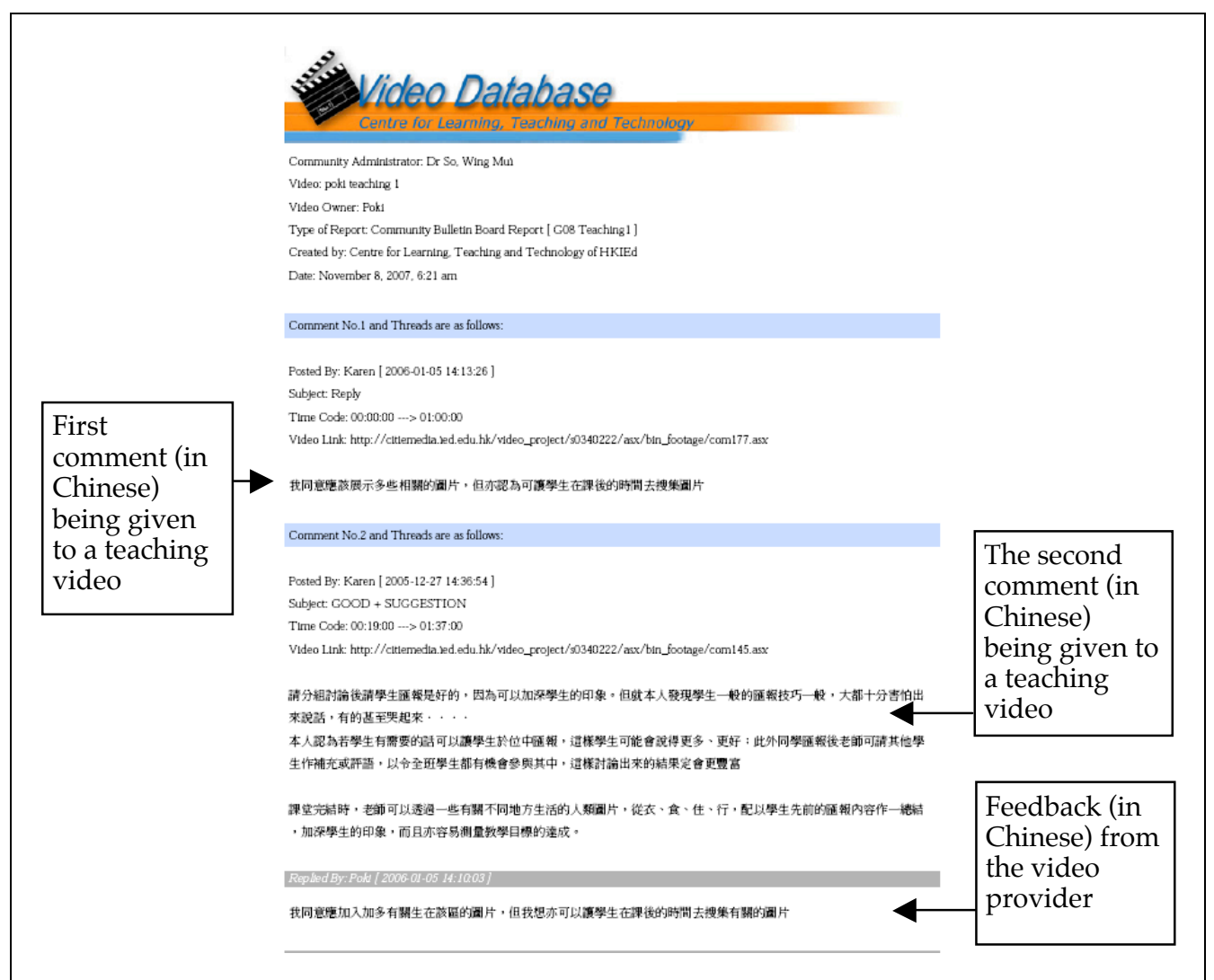

Figure 8: The PDF file conversion of feedback and comments

\section{Methodology}

Three student teachers used to working in the same group with their module studies were allocated to different schools for their first teaching practicum. Their collaboration and support among each other seemed to be diminished as a result of the distance barrier due to practicum placement allocation. The online video database apparently became a solution for them to continue their mutual support notwithstanding the geographic separation. Hence, they were invited to trial the digital video database to create an online virtual learning community during their teaching practicums.

Since the objective of the study was to explore how the interactive functions of the video database helped student teachers acquire knowledge of good teaching practices by sharing and receiving suggestions from other members of the learning community, 
the participating student teachers were required to provide videos showing their teaching in the classrooms. The recording of teaching was done by the student teachers, setting up camera and microphones by themselves in their own classrooms. The student teacher then followed the instruction guide provided by the researchers to upload the whole segment of teaching, which was of 30-40 minutes, to the Transaction Bin of the video database. During free time whenever they had access to computers, the student teachers could view the videos provided by the other community members and employ the 'Mark-In/ Out' function to match the feedback or comment with the exact timeline of the videos.

Adopting the concept of learning objects, student teachers wrote short descriptions to be shared with the learning community, with these small sessions ranging from a few seconds to a few minutes related to particular parts of teaching. Members were required to indicate an overall remark about the teaching segment in a positive connotation like 'Good', 'Suggestions', or "Good with suggestions' as the subject of the comment before they started working on the teaching videos. The general remark of "Good" represented satisfactory teaching performance, "Suggestion" represented problems identified with the teaching performance, and "Good with suggestion" represented positive feedback toward the teaching segment but there is still room for improvement. The video providers and other community members could then view the comments with reference to the marked sessions of clips, through the hyperlink in the Bulletin Board, and post feedback to each of the comments, if there was any.

\section{Data analysis}

A qualitative research design was used in this study for data analysis. Since the peer evaluation with comments on specific video segment and feedback provided by the video providers was in Chinese, it was translated into English during data analysis in order to answer the first two research questions. The analysis helped identify how comments and feedback flowed within the learning community and how the learning objects generated various categories of comments and responses, for a better understanding of how the video database supported student teachers in constructing knowledge of good practices of teaching.

A 90-minute focus group discussion arranged by the teacher educator was held with the three participants, targeting the other two research questions. The discussion mainly focused on the learning process of student teachers in developing good teaching practices through the learning community and video database during the teaching practicum. Besides, the student teachers also discussed the constraints found in using the online digital video database and the barriers identified in conducting video shooting of lessons. The discussion was audio recorded with a research assistant also taking written notes. It was expected the focus group could help with the identification of factors affecting the learning effectiveness of the learning community and challenges the community members had faced.

\section{Results}

\section{Flow of comments and feedbacks within the learning community}

Though the number of participants in this study is small, it is encouraging that the three members of this small community continued their communication throughout the whole teaching practicum period to make the learning community work. An in 
depth analysis of this small learning community helps identify the flow of comments and feedback for better understanding of the pattern of sharing and communication among community members.

The three community members, Student Teacher 1 (ST1), Student Teacher 2 (ST2) and Student Teacher 3 (ST3) uploaded five lesson videos altogether, resulting in 41 posts within the learning community concerning teaching practices, of which 29 are comments made by the community members in watching the teaching videos, 11 are feedback provided by either the video providers or other community members in response to the comments, and one is a further comment provided by a community member (Table 1).

Table 1: Interactive nature of comments and feedbacks within the learning community

\begin{tabular}{|c|c|c|c|c|}
\hline $\begin{array}{c}\text { Video } \\
\text { no. }\end{array}$ & $\begin{array}{c}\text { Video } \\
\text { provider }\end{array}$ & $\begin{array}{c}\text { Comments from } \\
\text { community members }\end{array}$ & $\begin{array}{c}\text { Comments / feedback from } \\
\text { video provider / other } \\
\text { community members }\end{array}$ & $\begin{array}{c}\text { Further feedback } \\
\text { from community } \\
\text { members }\end{array}$ \\
\hline 1 & ST1 & $\begin{array}{l}4 \text { by ST2 } \\
4 \text { by ST3 }\end{array}$ & $\begin{array}{r}2 \text { by ST1 } \\
1 \text { by ST3 }\end{array}$ & 0 \\
\hline 2 & ST2 & $\begin{array}{l}2 \text { by ST1 } \\
2 \text { by ST3 }\end{array}$ & 2 by ST2 & 0 \\
\hline 3 & ST2 & $\begin{array}{l}2 \text { by ST1 } \\
2 \text { by ST3 }\end{array}$ & 2 by ST2 & 0 \\
\hline 4 & ST2 & $\begin{array}{l}2 \text { by ST1 } \\
3 \text { by ST3 }\end{array}$ & 1 by ST2 \\
\hline 5 & ST3 & $\begin{array}{l}4 \text { by ST2 } \\
4 \text { by ST1 }\end{array}$ & 3 by ST3 & 0 \\
\hline & Totals & 29 & 11 & 1 \\
\hline
\end{tabular}

Four patterns (Figure 9) are identified from the analysis of the flow of comments and feedback. These include: a) a community member gave comments to the video provider (18 posts); b) a third community member added comments in response to the previous comment (1 post); c) the video provider responded to the comments from the community member (9 posts); and d) a third community member responded to the interaction between the video provider and a community member (1 post).

The following is an example of a comment given by a community member (ST1) to the video provider (ST2) without further follow up feedback.

ST1 gave comment to ST2 on Video 4: The noisy environment of the classroom made the class difficult to control. Apart from rewarding students with stickers, their behaviour could be effectively controlled by the use of a combination of hard and soft techniques. Besides, it was a good idea to have pupils record the types of waste at home to be a follow-up activity of the lesson.

The following interactions show the posting of another message from community member (ST3), in response to ST2's comments, on the teaching video (Video 1) of ST1.

Comment given by ST2 on Video 1: Not all of the groups could finish the worksheets within the given time. The teacher should allocate different tasks to the groups before conducting the group activities. For example, instead of completing the entire worksheet, each group should be responsible for completing different parts of the worksheet. In this way students could have sufficient time to complete the given tasks and less time could be spent on the worksheet. 
Feedback given by ST3 in response to ST2's comment: I agreed with your suggestion, but from the video provided by ST1, I noticed that all the tasks have been completed by pupils by the end of the lesson.

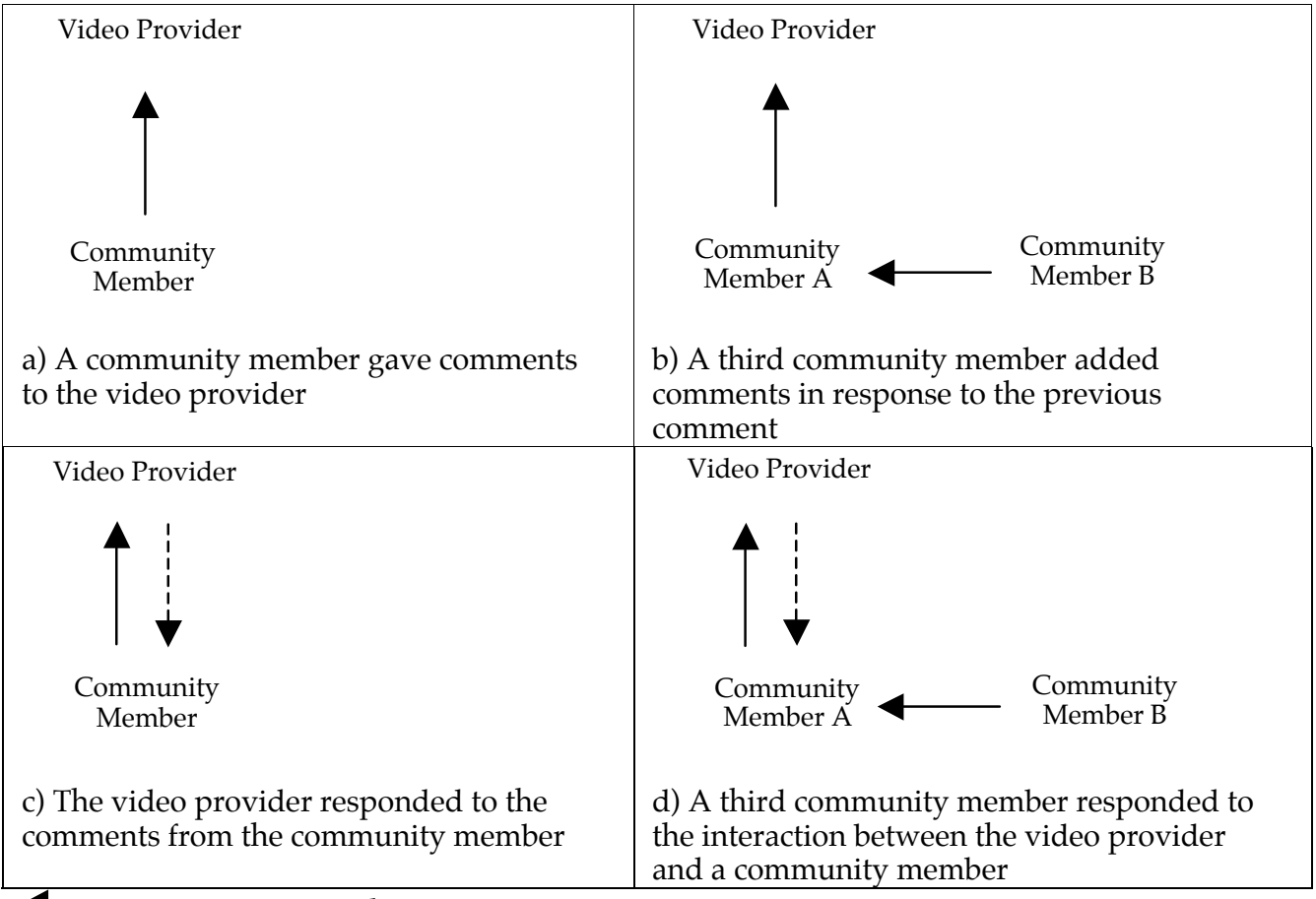

---- Feedback from the video provider

4 Comments from the community members

Figure 9: Four patterns identified from the analysis of the flow of comments

The following dialogue shows how the video provider (ST1) responded to the comments given by a community member (ST2) with explanation of what she had done during lesson preparation.

Comment given by ST2 on Video 1: The contents of the readers did not seem to match with the worksheet. This would affect the implementation of pupils' activities.

Feedback given by ST1 in response to ST2's comment on her teaching: Most contents required by the worksheets were very general, answers could be found in almost readers. I agreed that some readers have more in-depth information while others are rather simple. Actually, all of the above factors have been considered during the design of the worksheet, but due to my limited experiences in teaching, it was the best that I could have come up with at that moment.

In the following dialogue, community members gave encouragement and support to each other, with interactive flow of comments and feedbacks among the community members.

Comment given by ST1 on Video 3 provided by ST2: It was good and efficient to use a questioning approach to help pupils revise what they had learned in the previous lessons. The only down side was that the questioning was rather time consuming and tedious. 
Feedback given by ST2 in response to ST1's comment on his teaching in Video 3: I agree with your observation. To shorten the time and prevent pupils from losing interest, the questions should be clear, simple, and carefully organized. I also recognise the long questioning session made the lesson tedious. One of the reasons for the inappropriate time management in teaching might due to the crash of room-usage with another teacher, resulting in a disturbance of the original teaching plan.

Further feedback given by ST3 in response to ST2: Yes, unanticipated incidents happened in class were beyond teachers' ability to handle and might affect pupils' learning.

\section{Nature and categories of comments and responses}

The classification of the 41 comments posted on the video database is not easy because some of them dealt with more than one category of teacher performance. This is resolved by sorting out all the different views from each of the comments that comprises more than one view. The analysis of the nature and categories of the 41 comments found 90 remarks falling into the following categories (Table 2): a) the majority $(84 \%)$ of the remarks cover the teacher's performance in five categories, classroom management, teaching design, teaching technique, teacher effectiveness and use of resources; and b) $16 \%$ of the remarks focus on pupil behaviour and pupil participation. The proportion of remarks indicating 'Good' (39\%), 'Good with suggestions' (35\%) and 'Suggestions' (26\%) on the videos are found to be similar.

Table 2: Types of remarks given on the 41 comments and feedbacks $(n=90)$

\begin{tabular}{|l|c|c|c|c|c|c|c|c|}
\hline Videos & $\begin{array}{c}\text { Classroom } \\
\text { management }\end{array}$ & $\begin{array}{c}\text { Teaching } \\
\text { design }\end{array}$ & $\begin{array}{c}\text { Teaching } \\
\text { technique }\end{array}$ & $\begin{array}{c}\text { Teaching } \\
\text { effectiveness }\end{array}$ & $\begin{array}{c}\text { Use of } \\
\text { resources }\end{array}$ & $\begin{array}{c}\text { Pupil } \\
\text { discipline }\end{array}$ & $\begin{array}{c}\text { Pupil } \\
\text { participant }\end{array}$ & $\begin{array}{c}\text { Sub- } \\
\text { total }\end{array}$ \\
\hline Video 1 & 1 & 0 & 6 & 3 & 6 & 0 & 2 & 18 \\
\hline Video 2 & 2 & 2 & 5 & 3 & 1 & 2 & 0 & 15 \\
\hline Video 3 & 1 & 1 & 9 & 1 & 2 & 1 & 3 & 18 \\
\hline Video 4 & 1 & 3 & 5 & 5 & 4 & 3 & 2 & 23 \\
\hline Video 5 & 0 & 6 & 7 & 0 & 2 & 0 & 1 & 16 \\
\hline Subtotal & 5 & 11 & 32 & 12 & 16 & 6 & 8 & 90 \\
\hline
\end{tabular}

The followings are comments made by ST3 and ST2 on the use of resources and teaching design marked as 'Good', signifying that the community members appreciated the successful teaching performance of their peers.

ST3: The teacher paused the tape at the right time to ensure pupils were paying attention. And worksheets were provided to pupils to give them some ideas on the content of the lesson. (Comment 4 on Video 4)

ST2: The design of group activity could effectively facilitate pupils' collaboration. (Comment 4 on Video 1)

The followings are comments made by ST2 and ST1 on use of resources and pupil participation respectively, with 'Good with suggestion' indicating that the community members suggested alternatives for peers' consideration in their teaching.

ST2: It is good for the teacher to display related photos/diagrams during pupils' presentations. This could help pupils have a concrete and better understanding. But the photos focused mainly on topics related to 'human adaptation to the environment', it would be better for the teacher to have photos on other aspects in order to provide pupils with a holistic. (Comment 5 on Video 5). 
ST1: The idea of having pupils reported after group discussion is good as it might enhance pupils' learning. But it is also noted that their reporting skill was not good and in most cases pupils were afraid of doing so - one student even broke into tears. In my opinion, pupils might have performed better if they were allowed to stay in their own seats while reporting. Moreover, the teacher should encourage other pupils to make comments on what the others had reported, which could promote pupils' participation and the outcome would surely be more fruitful. (Comment 2 on Video 5)

The following shows comments marked with 'Suggestion', made by ST1 about teaching technique and the use of resources respectively. In general, the community members are found to be making proposals for improving teaching and learning rather than negatively criticising one another.

ST1: During the discussion about 'what rubbish has been disposed of?', if the teacher had guided the pupils to think about separating the rubbish into reusable and nonreusable ones and identifying their usage, the discussion would have been more constructive and more in line with the theme than simply discussing what rubbish the students had disposed of. (Comment 1 on Video 2)

ST1: At the end of the lesson, pictures about the life of people from around the world (e.g. about clothing, transportation, accommodation and food, etc.) should be used to further enhance the students' knowledge on what they had learned during the lesson, and this could also be used for assessing the achievement of teaching objectives.

(Comment 2 on Video 5)

All comments on classroom management were marked as 'Suggestion' but the suggestions did not came in the same form. For example, one comment posted to Video 4 showed a community member proposing a different way of managing the class while the other one showed another community member more directly pointing out a problem in Video 4.

ST1: The teacher should reinforce pupils' incentives by rewarding pupils' good behaviour at the end of the lesson. On one hand, this could help encourage other pupils to exercise good behaviour. On the other hand, this would not attract too much pupils' attention to teacher's small gifts during lesson. (Comment 2 on Video 4)

ST3: While the teacher was checking answers with pupils, there were a few pupils talking to each other all the time but the teacher did not stop them. (Comment 3 on Video 4)

\section{Learning about good teaching practices with the video database}

The viewpoints of student teachers about learning good teaching practices with the video database during their teaching practicum are captured in the focus group discussion. During this, all participating student teachers agreed that the involvement in the learning community with the digital video database helped them develop better understanding of teaching techniques and good teaching practices. Both the video provider and the viewers benefited from the flow of suggestions and feedback among the members of the learning community. The following shows how the community members evaluated their learning about good teaching practices with their involvement in the learning community.

ST2: ST1 pointed out my problem of having a long questioning time, which I did not realise during the lesson. Her comment stimulates me to be aware of using simplified questions in a logical order in order not to bore the pupils. 
The analysis of comments posted by the community member at the online discussion forum provides evidence that the student teachers were able to reflect critically on the teaching of their peers as well as their own. They also took the opportunity to learn from each other's teaching in authentic situations.

ST1: I thought I have tried my best with the design of worksheet, but ST2 could still propose some suggestions for a better design of worksheets.

ST3: No matter how big or how small the problem in my teaching was identified, they enforced me to rethink what I have designed. Sometimes I could justify the rationale of my design was alright but sometimes I couldn't deny there was oversight with my original design.

The student teachers reported that by viewing the lesson videos provided by peers, they could also experience the practices of some unfavourable and ineffective teaching behaviours, and this alerted them to repeating the same behaviour in their own teaching. Besides, student teachers who posted the video could review their own teaching again after receiving comments from community members. In turn, the video providers could give further explanations to viewers by providing more background information and rationales on the teaching design or uses of resources. The followings were examples shared by the student teachers.

ST1: I did not agree with the way ST2 rewarded his pupils. Though he tried to explain the rationale behind, I do not think I would do the same in my teaching.

ST2: It seemed not easy to arrange an activity which involved pupils in reading information from books. ST1's lesson reminded me of the need of greater attention in conducting this type of pupil activity in the future.

The interaction and discussions among community members provide practical learning experiences to student teachers at a critical point in their professional development. They appreciated how these experiences helped them develop competence, improve techniques, create rich teaching resources, and share the joys and difficulties of teaching. Student teachers gained knowledge of effective classroom management strategies from each other and learned how to avoid ineffective classroom management behaviour. Finally, student teachers reported that the learning community did more than provide good opportunities for sharing of joy in their teaching experience, it also helped them relieve from the frustrations due to the problems faced during the teaching practicum period.

ST3: I appreciated a lot the opportunity to share our views which was the avenue for pressure release during the practicum. Yet, we could also share our good work. Appreciations from community members were encouraging.

\section{Difficulties in creating a learning community through a video database}

During the focus group discussion, the student teachers also shared their experiences and difficulties in the use of the database. The difficulties mentioned are mainly technical problems encountered in viewing video segments and the shooting of lessons.

The constraints of viewing the video segments

In using the video database for sharing, it seems better to divide the 30-minute video into shorter segments, or learning objects. However, student teachers reflected that it 
was difficult to make comments based on a very short video segment because they might not know the full lesson planning, background, or details of pupil behaviour and attitude.

In general, the smaller or more granular a resource, the greater the possibility it will be reused in another educational context as a learning object (Littlejohn, 2003). However, larger learning objects usually have greater educational value - it is often less time consuming to reuse a larger learning object, such as video of a whole lesson, rather than constructing a lesson from several smaller and components. Therefore, in terms of learning object size, there is often a tension between increasing educational value and maximising reusability (Littlejohn, 2003).

The barriers to video recording of lessons

It is evident from the analysis of the feedback and comments at the online discussion forum that the digital video database could support student teachers' resources sharing and knowledge building through interaction. Yet student teachers also indicated unexpected barriers to shooting video during the forum discussion which shed light on the possibility of video recording in authentic classrooms. The barriers exist at different levels, including the school level, teacher level and pupil level.

For the barriers at the school level, it is reported by one of the community members that the principal of his practicum school had reservations about the video recording of lessons. It is because the school principal worried that sharing of videos online might invade pupils' privacy if lesson videos were used improperly by others. Though the worry of the school principal was relieved by the declaration of the student teacher and the confirmation from the project team that the video database restricts public access by password protection, the concern is worth highlighting in the design of the video database, that restricted login with password and a closed community is important for addressing the issue of privacy.

The barrier related to the teacher level is mainly teachers' concerns about the additional workload in managing the video recording and follow up analyses, because it would take them substantial time and effort in the whole process of video recording, transforming and uploading; the viewing of videos to give comments; and providing feedback upon comments given by community members.

The student teachers also pointed out that some pupils in their classes were not used to being recorded with a video camera and therefore behaved inappropriately or abnormally. It is hoped that pupils would become more used to the camera as video recording is becoming more popular.

\section{Conclusion}

Ideally, a central unit or server would store all online teaching resources and host a mature searching engine so that the users could easily locate resources. However, because of the lack of a standardised teaching resources format and well developed categorisation and searching engine, users from other communities might face difficulties in accessing and sharing online resources. Eventually, the community users might have to undergo tedious administrative procedures before uploading resources to a central unit, to ensure effective and efficient management (Duncan \& Ekmekcioglu, 2003). Currently, it is still common for users to produce and save resources in various formats accessible to them, ignoring the possibility of cross- 
platform digital sharing. The digital video server designed and developed in this study, which requires users to save resources in a standard format and upload to a digital platform, facilitates the sharing, editing and downloading of videos among community members.

Involving student teachers in uploading their videos into the video database and sharing with each other good practices in teaching signifies an effective integration of video and online community technology. Student teachers are not alone in testing out their teaching theory with classroom practice. They can digitise their teaching practice into video, text and sound and upload to a sharing community for manipulation and re-segmenting (Goldman, 2007). Also, the findings from this study contribute a new approach to how educators can manage a digital video database by using text based retrieval techniques.

Moreover, this study shows that the use of a digital video database in teacher education is not limited to one way or top down applications by the teacher educator to student teachers in demonstrating good or bad practices of teaching. It can be expanded to encompass multi-user peer to peer interactive communication, to support student teachers' learning about teaching. Furthermore, an online video database can create a vibrant learning community in which peers share insights, ask questions and make suggestions. As the Transaction Bin function is evolved into Community Management, users of the video database are allowed to invite others to join the community that emerges from sharing positive feedbacks via marked and annotated videos.

The patterns of sharing in the learning community identified in this study are mainly "one off" comments coming from the community members, with about one third of the comments receiving feedback from the video provider, either responding or explaining the situations in more details. The few comments that received further feedback from another community member and with all three community members contributing to the discussion of the same episode of teaching, have provided useful information for future studies by teacher educators who wish to encourage more interactive sharing of experiences among community members by forming a discourse community (Goldman, 2007).

There is evidence that the design of the video database for student teachers to post their teaching practice videos for sharing has adopted the three areas of concern in knowledge building proposed by Bereiter (2003). Student teachers participated in a community to share their teaching practice with each other for viewing, interpretations and criticisms in order to build on each other's prior knowledge of good practice in teaching. Student teachers shared the same vision and responsibility to construct the knowledge related to good practice of teaching. Besides, good practice of teaching was not an isolated practice achieved by individual community members. Through collaborative contribution among members in the video database platform, further improvements of good practice in teaching could be achieved.

To conclude, though the original impetus for the establishment of a digital video database was to provide an online database for users to upload and download video teaching resources, the experience gained from the present study and its focus on teacher education with sharing of teaching practices, suggests that the greatest benefits of a digital video database come from its enabling and encouragement of student 
teacher interaction, with easy accessibility to the videos anytime and anywhere with an Internet connected computer.

It is encouraging in the present study that the three members of the small learning community continued their communication throughout the whole teaching practice period even though the number of participants is small. The way forward is to make use of the experience gained in this study which involved a detailed analysis of the flow of comments and feedbacks within the learning community of a small number of student teachers and extend it to a larger community of student teachers in the teacher education program. Also, a follow up study with the same community members in their second teaching practicum is a direction for future research towards examining virtual learning communities created with the help of the digital video database for teacher education.

\section{References}

Bereiter, C. (2003). Education in the knowledge age. Keynote speech at the Educational Research Conference at The University of Macau.

Ching, S. H. (2006). Developing student teachers' conceptions of good science teaching: The roles of video workshops. In J. Huang \& M. Y. Gu (Eds.), Research studies in education: Vol. 4 (pp. 222-235). Hong Kong: Office of Research, Faculty of Education, University of Hong Kong.

Duncan, C. \& Ekmekcioglu, C. (2003). Digital libraries and repositories. In A. Littlejohn (Ed.), Reusing online resources: A sustainable approach to e-learning (pp.135-145). Ebbw Vale: Creative Print and Design (Wales).

Goldman, R. (2007). Video representations and the perspectivity framework: Epistemology, ethnography, evaluation, and ethnics. In R. Goldman, R. Pea, B. Barron \& S. J. Derry (Eds.), Video research in the learning sciences. London: Lawrence Erlbaum Associates.

Haga, H. (2004). Concept of video bookmark (videomark) and its application to the collaborative indexing of lecture video in video-based distance education. International Journal on ELearning, 3(3), 32-37.

Haughey, M. \& Muirhead, B. (2005). The pedagogical and multimedia designs of learning objects for schools. Australasian Journal of Educational Technology, 21(4), 470-490. http:/ / www.ascilite.org.au/ajet/ajet21/haughey.html

Khine, M. S. \& Lourdusamy, A. (2003). Using Conversant Media as a collaborative learning tool in teacher education. Australian Journal of Educational Technology, 19(2), 260-274. http: / / www.ascilite.org.au/ajet/ ajet19/khine.html

Kurubacak, G. (2005). Learners and faculty creative partnerships through building a virtual community: Their experiences toward sharing knowledge online. In C. Crawford et al. (Eds.), Proceedings of Society for Information Technology and Teacher Education International Conference 2005 (pp. 2271-2278). Chesapeake, VA: AACE.

Littlejohn, A. (2003). Issues in reusing online resources. In A. Littlejohn (Ed.), Reusing online resources: A sustainable approach to e-learning (pp.1-8). Ebbw Vale: Creative Print and Design (Wales).

Luppicini, R. (2003). Categories of virtual learning communities for educational design. Quarterly Review of Distance Education, 4(4), 409-419. 
Marchionini, G. \& Geisler, G. (2002). The open video library. D-Lib Magazine, 8(12) [viewed 15 July 2003, verified 27 Dec 2007]

http:/ / www.dlib.org/dlib/december02/marchionini/12marchionini.html

Marques, O. \& Furht, B. (2002). Content-based visual information retrieval. In T. K. Shih (Ed.), Distributed multimedia databases: Techniques $\mathcal{E}$ applications (pp. 37-55). Hershey, PA: Idea Group Publishing.

Scardamalia, M. \& Bereiter, C. (2002). Knowledge building. In Encyclopedia of education (2nd ed.). New York: Macmillan.

Steketee, C. (2006). Modelling ICT integration in teacher education courses using distributed congnition as framework. Australasian Journal of Education Technology, 22(1), 126-144. http:/ / www.ascilite.org.au/ajet/ajet22/steketee.html

Tu, C. \& Corry, M. (2002). eLearning communities. Quarterly Review of Distance Education, 3(2), 207-218.

Wickersham, L. E. \& Dooley, K. E. (2006). A content analysis of critical thinking skills as an indicator of quality of online discussion in virtual learning communities. Quarterly Review of Distance Education, 7(2), 185-193.

Wiley, D. A. (2000). Connecting learning objects to instructional design theory: A definition, a metaphor, and a taxonomy. In D.A. Wiley (Ed.) The instructional use of learning objects. [viewed 15 July 2003, verified 27 Dec 2007] http:/ / reusability.org/ read/ chapters/ wiley.doc

Dr Winnie Wing-mui So, Associate Professor, Department of Mathematics, Science, Social Sciences and Technology, The Hong Kong Institute of Education, 10 Lo Ping Road, Tai Po, Hong Kong SAR. Email: wiso@ied.edu.hk

Mr Vincent Hing-keung Hung, Assistant Education Technology Officer, Centre for Learning, Teaching and Technology, The Hong Kong Institute of Education, 10 Lo Ping Road, Tai Po, Hong Kong SAR. Email: vhung@ied.edu.hk

Mr Walker Yee-wing Yip, Technician, Centre for Learning, Teaching and Technology, The Hong Kong Institute of Education, 10 Lo Ping Road, Tai Po, Hong Kong SAR.

Email: ywyip@ied.edu.hk 